\title{
Probiotic lactobacillus and estrogen effects on vaginal epithelial gene expression responses to Candida albicans
}

R Doug Wagner ${ }^{*}$ and Shemedia J Johnson

\begin{abstract}
Background: Vaginal epithelial cells have receptors, signal transduction mechanisms, and cytokine secretion capabilities to recruit host defenses against Candida albicans infections. This research evaluates how probiotic lactobacilli affect the defensive epithelial response.

Methods: This study used quantitative reverse transcription-polymerase chain reaction assay (qRT-PCR), flow cytometry, and a multiplex immunoassay to observe changes in the regulation of gene expression related to cytokine responses in the VK2 (E6/E7) vaginal epithelial cell line treated with 17ß-estradiol, exposed to probiotic Lactobacillus rhamnosus GR-1 ${ }^{\circledR}$ and Lactobacillus reuteri RC-14 ${ }^{\circledR}$ and challenged with C. albicans. Data were statistically evaluated by repeated measures analysis of variance and paired t-tests where appropriate.

Results: C. albicans induced mRNA expression of genes related to inflammatory cytokine responses associated with nuclear factor-kappa B (NF-kB) and mitogen-activated protein kinase (MAPK) signal transduction pathways. 17ß-estradiol suppressed expression of interleukin-1a (IL-1a), IL-6, IL-8, and tumor necrosis factor alpha (TNFa) mRNA. Probiotic lactobacilli suppressed C. albicans-induced nuclear factor-kappa B inhibitor kinase kinase alpha (IKKa), Toll-like receptor-2 (TLR2), TLR6, IL-8, and TNFa, also suggesting inhibition of NF-KB signaling. The lactobacilli induced expression of IL-1a, and IL-1 $\beta$ mRNA, which was not inhibited by curcumin, suggesting that they induce an alternate inflammatory signal transduction pathway to NF-KB, such as the mitogen activated protein kinase and activator protein-1 (MAPK/AP-1) signal transduction pathway. Curcumin inhibited IL-13 secretion, suggesting that expression of this cytokine is mainly regulated by NF-KB signaling in VK2 cells.
\end{abstract}

Conclusions: The results suggest that $C$. albicans infection induces pro-inflammatory responses in vaginal epithelial cells, and estrogen and lactobacilli suppress expression of NF-kB-related inflammatory genes. Probiotic lactobacilli may induce IL-1 $a$ and IL-1 $\beta$ expression by an alternate signal transduction pathway, such as MAPK/AP-1. Activation of alternate signaling mechanisms by lactobacilli to modify epithelial cell cytokine production may be a mechanism for probiotic modulation of morbidity in vulvovaginal candidiasis.

Keywords: Probiotic, Epithelial cells, Gene expression, Signal transduction genes, Candidiasis, Estrogen

\section{Background}

The vaginal microbiota is one of the first lines of defense against vulvovaginal candidiasis (VVC). The normal vaginal microbiota is predominantly populated by Lactobacillus crispatus, Lactobacillus jensenii, and Lactobacillus iners [1], which tend to suppress growth of other bacterial species by production of lactic acid and antimicrobial

\footnotetext{
* Correspondence: doug.wagner@fda.hhs.gov

Microbiology Division, National Center for Toxicological Research, 3900 NCTR Rd, Jefferson, AR 72079, USA
}

products [2]. Some in vivo experiments have shown that the strains L. rhamnosus GR-1 and L. reuteri RC-14 may be effective treatments for VVC [3]. These organisms may partially affect resistance to yeast infections by modulating the pro-inflammatory responses of vaginal epithelial cells to the fungus.

The vaginal epithelial cell is the next line of defense against Candida spp. in the vagina. These epithelial cells have anti-Candida spp. activity, which is reduced in women with recurrent VVC [4]. The predominant mode 
of protection against VVC has shifted in the estimation of some scientists from adaptive immunity to innate immunity, which may be responsible for symptomatic presentation of the disease [5]. The vaginal epithelial cell can be considered part of this innate defense system, as it is capable of producing pro-inflammatory cytokines. These cells are known to send Langerhans cell recruitment signals in the form of the CCL20 chemokine [6] and they also express other immune recruitment molecules [7]. Epithelial cells of the human genitourinary tract respond to microbial surface molecules with Toll-like receptors-2, 4 , and 6 that initiate transcription of pro-inflammatory cytokines, such as interleukin-8 (IL-8), IL-6, IL-1 $\alpha$, IL$1 \beta$, and tumor necrosis factor alpha (TNF $\alpha$ ) by way of the nuclear factor-kappa B (NF- $\mathrm{B})$ signal transduction pathway $[8,9]$. Other microbial surface molecule pattern recognition molecules and signal transduction pathways may also be involved in pro-inflammatory epithelial cell responses. Recognition of surface molecular patterns of probiotic bacteria by VEC may account for some of their ability to modify host responses to C. albicans.

Estrogens appear to affect the recruitment of host defenses to $C$. albicans by epithelial cells of the female reproductive tract. For example, primary uterine epithelial cells respond to estrogen with decreased secretion of lipopolysaccharide-induced cytokines, IL-6, IL-8, and macrophage migration inhibition factor [10]. Expression of the regulatory protein NF- $\mathrm{kB}$ is also decreased in these cells by estrogen, which may cause decreased expression of cytokine genes, such as IL- 6 , IL- 8 , IL- $1 \alpha$, IL- $1 \beta$, TNF $\alpha$, and others under its regulation. Thus, estrogen may be an important factor affecting the barrier and host defense recruitment functions of the vaginal epithelium as well, and its role must be assessed in conjunction with studies of probiotic lactobacilli effects.

The present study was done to evaluate effects of probiotic lactobacilli on VVC at the point of fungal contact with vaginal epithelial cells with estrogen present in the form of $17 \beta$-estradiol. The effects of probiotic lactobacilli on how the VK2 cell model of vaginal epithelial cells respond to contact with C. albicans, with and without the influence of estrogen, was studied at the level of expression of genes for intracellular signal transduction mechanisms and intercellular signaling by cytokines.

\section{Methods}

\section{Microbial strains and growth conditions}

Candida albicans strain B 311 (ATCC 32354) was grown aerobically overnight in Sabouraud's dextrose broth (Thermo Fisher Scientific, Houston, TX) at $37{ }^{\circ} \mathrm{C}$. $L$. rhamnosus GR-1 ${ }^{\circledR}$ and L. reuteri $\mathrm{RC}-14^{\circledR}$ (provided by Dr. Gregor Reid, Urex Bioscience, London, Ontario) were grown anaerobically in MRS broth (Thermo Fisher) at $35^{\circ} \mathrm{C}$.

\section{Culture and microbial challenge of VK2 cell line}

The VK2 (E6/E7) vaginal epithelial cell line (VK2) [11], purchased from the American Type Culture Collection, Rockville, MD, as product CRL-2616, was grown to confluence as polarized monolayers on $35 \mathrm{~mm}$ polycarbonate inserts $[7,12]$ in keratinocyte-serum free medium (K-SFM) containing $5 \mathrm{ng} / \mathrm{ml}$ recombinant epidermal growth factor and $50 \mu \mathrm{g} / \mathrm{ml}$ bovine pituitary extract (Invitrogen Corporation, Grand Island, NY) and some experimental groups contained $10 \mathrm{nM} 17 \beta$-estradiol added to the basolateral medium [13]. Genital tract secretions (GTS) medium [14] was used on the apical side of the VK2 cell monolayers. The cells were grown at $37^{\circ} \mathrm{C}$ with a $5 \% \mathrm{CO}_{2}$ atmosphere and $100 \%$ humidity. Confluence, polarization, and differentiation of the VK2 cell monolayers were assessed by measurement of trans-epithelial electrical resistance (TEER) with an EVOM device (World Precision Instruments, Inc., Sarasota, FL). Viability of the VK2 cell monolayers were assessed by measurement of lactate dehydrogenase (LDH) released into the basolateral medium after experimental treatments using a commercial assay kit (Takara LDH cytotoxicity detection kit, Thermo Fisher). Probiotic lactobacilli were added at $1 \times 10^{7} \mathrm{CFU} / \mathrm{ml}$ to the apical culture chambers $4 \mathrm{hr}$ before an 18 hour challenge with $2 \times 10^{6} \mathrm{CFU} / \mathrm{ml} \mathrm{C}$. albicans. The six experimental groups compared in this study were: (1) VK2 cells grown $18 \mathrm{hr}$ with K-SFM medium on the basolateral sides and GTS medium on the apical sides of the culture inserts, (2) VK2 cells cultured in the same media and challenged with $2 \times 10^{6}$ CFU C. albicans, (3) VK2 cells with $10 \mathrm{nM} 17 \beta$-estradiol in the basolateral medium, (4) VK2 cells in the same media with $10 \mathrm{nM}$ $17 \beta$-estradiol added to the basolateral medium and challenged with $2 \times 10^{6}$ CFU C. albicans, (5) VK2 cells incubated 22 hours with $1 \times 10^{7} \mathrm{CFU}$ of both Lactobacillus strains in the apical GTS medium, and (6) VK2 cells cultured with $10 \mathrm{nM} 17 \beta$-estradiol added to the basolateral medium and pre-incubated 4 hours with 1 X $10^{7} \mathrm{CFU}$ of both Lactobacillus strains before challenge with $2 \mathrm{X}$ $10^{6}$ CFU C. albicans. The final incubations were 18 hours after C. albicans challenge.

\section{Real-time RT-PCR gene expression profiling}

Total cellular RNA samples from VK2 cell monolayers were isolated using RNeasy Protect ${ }^{\mathrm{TM}}$ total RNA isolation kits (Qiagen, Inc., Valencia, CA). The RNA samples were reverse-transcribed with the $\mathrm{RT}^{2} \mathrm{PCR}$ Array $^{\mathrm{Tm}}$ first strand kit (SABioscience, Fredrick, $\mathrm{MD}$ ) and the resulting cDNA were applied to real-time PCR using $\mathrm{RT}^{2}$ Profiler $^{\mathrm{Tm}}$ kits (SABioscience) for detection in a BioRad (Hercules, CA) Pci,Q5 instrument. The $\mathrm{RT}^{2}-$ Profiler $^{\text {TM }}$ kits used in the study were: PAHS-011A Human Inflammatory Cytokines and Receptors, PAHS-052A Human Innate and Adaptive Immune Responses, PAHS-025A 
Human NF-кB Signaling Pathway, PAHS-077A Human Inflammatory Response and Autoimmunity, PAHS-014A Human Signal Transduction Pathway Finder; together, they measured mRNA levels of 145 genes associated with innate immune cell signaling. The PAHS-999A Human $\mathrm{RT}^{2}$ RNA QC PCR Array was used to validate the quality of the cDNA products prior to real-time PCR analysis. The $\mathrm{RT}^{2}$ PCR Array ${ }^{\mathrm{TM}}$ products contain primers for housekeeping genes: beta-2 microglobulin, hypoxanthine phosphoribosyl transferase 1 , ribosomal protein L13a, glyceraldehyde-3-phosphate dehydrogenase, and beta actin, which are used by the analysis software as internal controls. Results of the PCR array experiments were analyzed with online software at SABioscience to determine the key signal transduction pathways and immune system interaction genes affected by C. albicans, $17 \beta$-estradiol, and the probiotic Lactobacillus spp. strains. The software calculated fold changes in mRNA concentrations using the formula: $2^{-\Delta \mathrm{Ct}}$ test sample $/ 2^{-\Delta \mathrm{Ct}}$ control sample. The average $\Delta \mathrm{Ct}$ values of test $(n=6)$ samples were corrected for average $\Delta \mathrm{Ct}$ values of 5 housekeeping genes before inclusion in the formula. Comparisons of average $\Delta C t$ values of test $(n=6)$ samples were statistically significant according to the t-test at $\mathrm{P}<0.05$. Average changes of two-fold or more in expression of genes were considered significant.

\section{Flow cytometric analysis of gene products}

Flow cytometry with an Accuri C6 cytometer (Accuri Cytometers, Ann Arbor, MI) using fluorescently labeled antibodies from Santa Cruz Biotechnology, Santa Cruz, CA and Biolegend, San Diego, CA, was used to compare the phenotypic responses in the VK2 cells to the genotypic responses measured with the quantitative real-time RT-PCR profiles.

VK2 cells incubated with $10 \mathrm{nM} 17 \beta$-estradiol and an equal mixture of probiotic strains or with $10 \mathrm{nM} 17 \beta$ estradiol alone were challenged with $C$. albicans, as described above and then stained with fluorescent antibodies for surface receptors prior to analysis by flow cytometry. Ten thousand events were accumulated from each analysis for comparison between experimental groups. Many of the signal transduction antigens of interest are only expressed intracellularly, so Santa Cruz Biotechnology intracellular flow cytometry staining kits were used to prepare the cells for analysis.

Extracellular and intracellular staining methods were used as described by the antibody manufacturers. Antibodies were applied at concentrations recommended by the manufacturers, usually $1 \mu \mathrm{g} / \mathrm{ml}$ for 1 X $10^{6}$ cells. The stained cells were suspended in $1 \%$ paraformaldehyde PBS solution (Boston Bioproducts, Inc., Worcester, MA).

The flow cytometer was calibrated with SPHERO $^{\text {tw }}$ Rainbow 8-Peak and Allophycocyanin 6-Peak calibration particles (Spherotech, Inc., Lake Forest, IL). After 10,000 cells were counted in a sample, a density plot of measurements from side scatter versus the appropriate fluorescence channel was analyzed with a polyhedral gate to determine the percentage of stained cells. Averaged relative fluorescence values were compared to assess significant changes in expression of specific genes at the level of protein expression.

\section{Quantitative cytokine immunoassay}

A MultiBead ${ }^{\circledR}$ multiplex immunoassay (Enzo Life Sciences, Ann Arbor, MI) was used to quantify cytokines excreted into the basolateral growth media by VK2 cells. Using the manufacturer's instructions, culture supernatants were incubated with allophycocyanin -labeled $4 \mu \mathrm{m}$ and $5.4 \mu \mathrm{m}$ anti-human cytokine antibody-coated capture beads that were washed in 96 well filter plates on a vacuum manifold (Enzo) set at 100 mbar vacuum. The beads were incubated with phycoerythrin-labeled streptavidin and washed on the vacuum manifold. The beads were analyzed in a $\mathrm{C6}^{\circledR}$ digital flow cytometer (Accuri Cytometers) that was calibrated with Rainbow 8-peak ${ }^{\circledR}$ and Allophycocyanin 6-Peak Calibration Particles $^{\circledR}$ (Spherotech). Each size bead population was gated with forward and side scatter dot plots and individual allophycocyanin fluorescence intensities corresponding to specific anti-cytokine antibody were gated with an emission detector filtered at $675 \mathrm{~nm}$ (FL-4) after excitation with a $640 \mathrm{~nm}$ laser. Fluorescence of phycoerythrin was used to obtain quantitative information by excitation with a laser at $488 \mathrm{~nm}$ and detection at $585 \mathrm{~nm}$ (FL-2). Results were obtained from a standard curve in Assay Designs MultiBead ${ }^{\circledR}$ analysis software using standards supplied by the kit manufacturer (Enzo).

\section{NF-KB signal transduction pathway inhibition}

The inhibitor of NF- $\mathrm{kB}$ nuclear transduction, curcumin (Imgenex, San Diego, CA), was used to assess whether probiotic effects on VK2 cell cytokine responses were mediated exclusively by the NF- $\mathrm{kB}$ signal transduction pathway. VK2 cells grown to confluence on polyester inserts, as described above, were divided into four experimental groups: (1) VK2 cells, (2) VK2 cells $+100 \mu \mathrm{M}$ curcumin, (3) VK2 cells + lactobacilli and, (4) VK2 cells + lactobacilli $+100 \mu \mathrm{M}$ curcumin. The apical medium was GTS [14]. For groups 2 and 4, the basolateral media were replaced with curcumin solution and incubated $4 \mathrm{hr}$ at $37{ }^{\circ} \mathrm{C}$. Groups 3 and 4 received 1 X $10^{7} \mathrm{CFU} / \mathrm{ml}$ of the Lactobacillus mixture and were incubated 18 hours. After incubation, media from the inserts (apical) and the wells (basolateral) were centrifuged at 10,000 $\mathrm{x} g$ for $2 \mathrm{~min}$ and the supernatants were assayed with the MultiBead ${ }^{\circledR}$ multiplex immunoassay to determine cytokine concentrations. 


\section{Analysis of data}

The mean fold differences in expression of genes detected by the $\mathrm{RT}^{2} \mathrm{PCR}$ arrays and curcumin inhibition of cytokine production assays from 6 independent experiments per treatment group were compared for statistical significance with the Repeated Measures OneWay Analysis of Variance and Newman-Keuls post tests [15] using Prism v. 5.0 software (GraphPad Software, San Diego, CA). Paired comparisons of flow cytometry and cytokine immunoassay data were made with paired t-tests in Prism v. 5.0 software to assess statistically significant differences. Statistical significance was defined as $\mathrm{P}<0.05$.

\section{Results}

Epithelial permeability, but not viability was affected by estrogen and microbes

The integrity of a VEC monolayer can be disturbed by hormones and microbial activity. The presence of $C$. albicans appeared to increase the TEER of the VEC monolayers of most samples, but the effect was not statistically significant (Figure 1). When 17 $\beta$-estradiol was incubated with the cells alone, there was a significant increase in TEER, but when VK2 cells were treated with $17 \beta$-estradiol and $C$. albicans-challenged, the TEER values were significantly reduced (Figure 1). The probiotic lactobacilli did not significantly alter the TEER values of VK2 cells alone or modify the reduced TEER values of VK2 cells treated with $17 \beta$-estradiol and challenged with $C$. albicans (Figure 1). These results suggest that $17 \beta$-estradiol effects on $C$. albicans infectivity may damage the cell monolayer, rather than changes in tight junctions, leading to the reduced electrical resistance.

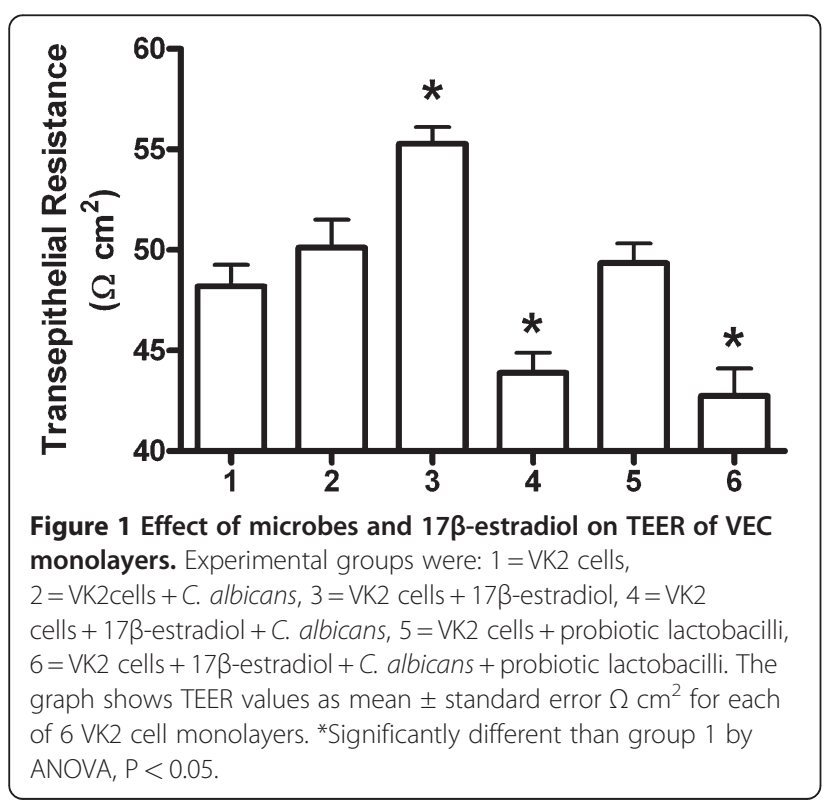

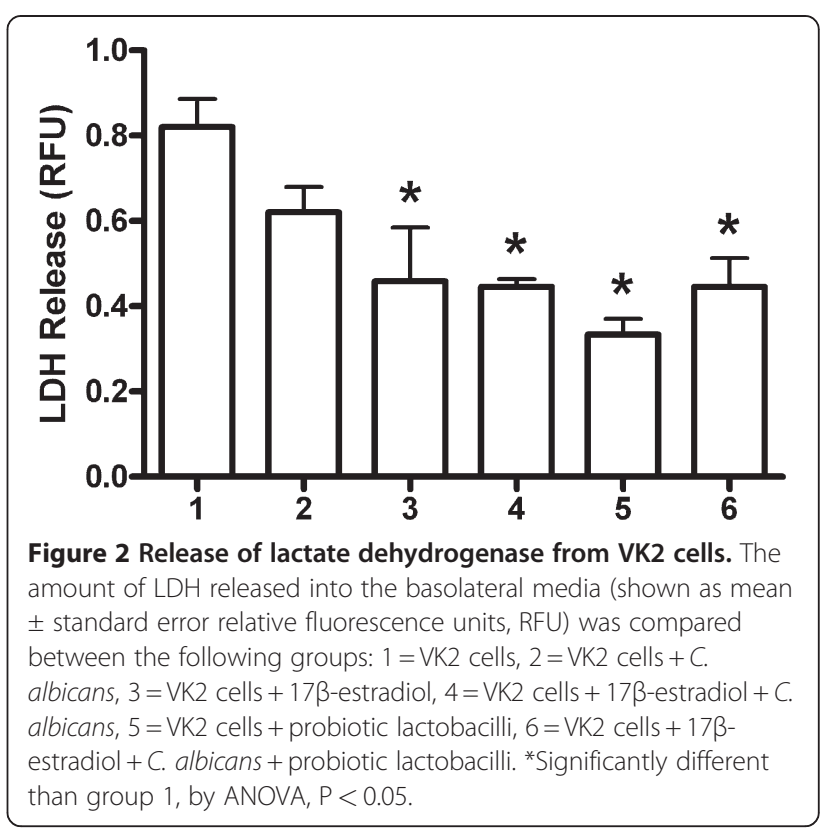

To test this, cell damage was assessed by LDH release into the basolateral medium. Infection of $\mathrm{VK} 2$ cell monolayers with $C$. albicans would be expected to cause some cell damage. Small amounts of LDH could be detected in the basolateral media from VK2 cell cultures. All the treatment groups (except C. albicans-challenged) appeared to have lower amounts of LDH in the basolateral media than VK2 cells cultured alone (Figure 2). This suggests that the treatments, including $C$. albicans contact did not induce necrosis of the VK2 cells.

Inflammatory gene expression responses by VK2 cells to C. albicans are influenced by $17 \beta$-estradiol and lactobacilli Receptors on epithelial cell surfaces detect microbes and convey the messages of detection through intracellular signal transduction pathways to nuclear transcription sites that code for response genes, such as cytokines. The expression of the genes involved in intracellular signal transduction may also be affected by cellular contact with microbes. In this study, real-time RT-PCR panels were used to measure differences in mRNA expression of microbial receptors and genes involved in intracellular and extracellular signal transduction. Table 1 shows fold-change in expression of mRNA in VK2 cells after each treatment, as compared with the level of mRNA expression in untreated VK2 cell controls. Effects on mRNA concentrations from VK2 cells treated with $C$. albicans, $17 \beta$-estradiol, and probiotic lactobacilli alone or in combinations were compared for 2-fold or greater changes in expression between columns in the table. $C$. albicans infection significantly induced VK2 cell mRNA expression of the pro-inflammatory cytokine gene IL-6 and the ELK1 gene involved in pro-inflammatory signal 
Table 1 Changes in expression of genes affected by experimental treatments

\begin{tabular}{|c|c|c|c|c|c|}
\hline \multirow[b]{2}{*}{ Gene mRNA/Function } & \multicolumn{5}{|c|}{$\begin{array}{l}\text { Fold changes in mRNA } \\
\text { expression vs. control }\end{array}$} \\
\hline & $\mathrm{Ca}$ & $E_{2}$ & $\mathrm{Ca}+\mathrm{E}_{2}$ & $\mathrm{~Pb}$ & $\mathrm{Ca}+\mathrm{E} 2+\mathrm{Pb}$ \\
\hline $\begin{array}{l}\text { ELK1/Inflammatory } \\
\text { transcription factor }\end{array}$ & +2.49 & -3.06 & +1.59 & -4.46 & +1.09 \\
\hline $\begin{array}{l}\text { Ikka/Induces NF-kB } \\
\text { nuclear translocation }\end{array}$ & +1.68 & -1.70 & +1.09 & -2.68 & -3.04 \\
\hline IL-1a/Inflammatory cytokine & -1.64 & -2.46 & -1.39 & +2.93 & +3.77 \\
\hline L-1ß/Inflammatory cytokine & +1.86 & +4.45 & +1.64 & +36.18 & +3.80 \\
\hline IL-6/Inflammatory cytokine & +2.36 & -1.74 & +1.16 & -1.35 & -1.01 \\
\hline IL-8/Inflammatory cytokine & +1.24 & -3.99 & +2.59 & +10.70 & -1.02 \\
\hline $\begin{array}{l}\text { TLR2/Inflammatory } \\
\text { receptor for microbes }\end{array}$ & +1.10 & -1.39 & -2.33 & -1.22 & -3.37 \\
\hline $\begin{array}{l}\text { TLR6/Inflammatory } \\
\text { receptor for microbes }\end{array}$ & -1.09 & -5.64 & -1.93 & -2.94 & -5.08 \\
\hline TNFa/Inflammatory cytokine & +1.85 & -9.32 & +1.37 & -5.78 & -6.78 \\
\hline
\end{tabular}

Fold changes in mRNA expression were derived from the average values of real-time PCR threshold concentrations ( $n=6, P<0.05$ by $t$-test) for each gene of interest compared to housekeeping genes. Abbreviations: $(\mathrm{Ca}) \mathrm{C}$. albicans, (E2) $17 \beta$-estradiol, $(\mathrm{Pb})$ probiotic lactobacilli, an equal mixture of $L$. rhamnosus GR-1 and L. reuteri RC-14.

transduction. The presence of $17 \beta$-estradiol alone induced VK2 cell expression of IL-1 $\beta$, a pro-inflammatory response. VK2 cells responded differently to $17 \beta$-estradiol when $C$. albicans was not present, as they had reduced expression of ELK1, IкK $\alpha$, IL-1 $\alpha$, IL-6, IL-8, TLR6, and TNF $\alpha$. It caused a 2-fold decrease in expression of TLR2 by C. albicans-infected VK2 cells (Table 1 ). $17 \beta$-estradiol also did not significantly alter expression of IL- $1 \alpha$, IL- $1 \beta$, IL-6, IL8, or TNF $\alpha$ mRNA expression in C. albicansinfected VK2 cells.

Probiotic lactobacilli induced VK2 cell mRNA expression of the inflammatory cytokines IL-1 $\alpha$, IL- $1 \beta$, and IL8 (Table 1). Interestingly, IL-8 mRNA induction in VK2 cells by the lactobacilli was apparently blocked by $17 \beta-$ estradiol. The probiotic lactobacilli did not add to increased expression of any genes induced by $C$. albicans in the presence of $17 \beta$-estradiol. Expression of some pro-inflammatory genes was suppressed by the presence of the lactobacilli, including: ELK1, IкK $\alpha$, IL-6, TLR6, and TNF $\alpha$ (Table 1). The presence of probiotic lactobacilli suppressed $C$. albicans induction of ELK1, IкK $\beta$, and IL-6 in the presence of $17 \beta$-estradiol. Although $17 \beta$ estradiol suppressed expression of pro-inflammatory genes in VK2 cells, it did not suppress expression of pro-inflammatory genes induced by $C$. albicans, which was a feature of probiotic lactobacilli. Some cytokine genes expressed by other types of cells, such as lymphocytes, were not observed to be expressed by VK2 cells, including: IL-2, IL-4, IL-10, and TGF $\beta$. The expression profile in VK2 cells resulting from the influence of probiotic lactobacilli was mostly anti-inflammatory, but lactobacilli induced IL- $1 \alpha$ and IL-1 $\beta$ mRNA expression, perhaps by an alternative signal transduction response pathway to NF-kB.

\section{Lactobacilli suppressed inflammatory signaling protein expression}

Effects of probiotic bacteria on expression of some of the signaling molecules and cytokines were assessed at the level of protein expression in the cells by flow cytometry. Figure 3 shows a comparison of VK2 cells expression of signal transduction proteins after incubation with C. albicans and $17 \beta$-estradiol with VK2 cells incubated with the probiotic lactobacilli, C. albicans, and $17 \beta-$ estradiol. As with mRNA expression, the expression of pro-inflammatory proteins was suppressed by lactobacilli. Figure 3 shows that expression of $C$. albicans-inducible ELK1, and Ікк $\beta$ was suppressed by the probiotic lactobacilli. It also shows that VK2 cell expression of other inflammatory proteins, TLR2, TLR6, IKK $\alpha$, and TNF $\alpha$ that were not significantly induced by $C$. albicans were decreased by the lactobacilli.

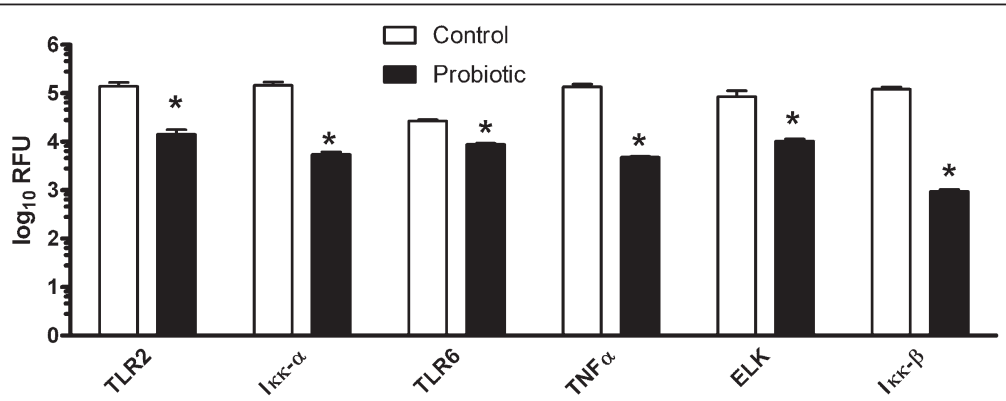

Figure 3 Effects of estrogen, C. albicans and lactobacilli on VK2 cell expression of signal transduction and cytokine molecules. The mean \pm standard error relative fluorescence of cells from 6 experiments/group, that were stained with specific fluorescently labeled antibodies and detected by flow cytometry, are compared between (open bars) VK2 cells incubated with 17ß-estradiol, challenged with C. albicans and (solid bars) VK2 cells cultured with $17 \beta$-estradiol, probiotic lactobacilli and challenged with C. albicans. *The pairs of bars were significantly different from each other (determined with paired t-tests, $P<0.05$ ). 


\section{Probiotic lactobacilli modulated VK2 cell secretion of immune cell recruitment cytokines}

Since mRNA expression levels of inflammatory cytokines were affected by $17 \beta$-estradiol and probiotic lactobacilli, concentrations of those cytokines secreted into the basolateral growth medium by VK2 cells were measured with a quantitative multiplex immunoassay. The VK2 cells did not secrete detectable levels of IFN- $\gamma$, RANTES, IL-2, IL-4, IL-5, IL-10, or IL-17. The presence of $10 \mathrm{nM} 17 \beta$-estradiol caused C. albicans-infected VK2 cells to secrete significantly more IL-8 from $487 \pm$ $33 \mathrm{pg} / \mathrm{ml}$ to $1057 \pm 117 \mathrm{pg} / \mathrm{ml}$. This $17 \beta$-estradiolinduced expression of IL-8 in C. albicans-infected VK2 cells appeared to be blocked by probiotic lactobacilli (Figure 4). Probiotic lactobacilli significantly increased IL- $1 \alpha$ secretion, but not IL-1 $\beta$ secretion by VK2 cells in the presence of $17 \beta$-estradiol and C. albicans (Figure 4). This effect was not inhibited by curcumin, suggesting that NF- $\mathrm{kB}$ signaling was not necessary to mediate these changes in expression of IL- $1 \alpha$ (Figure 5). The probiotic lactobacilli alone significantly decreased C. albicansinduced secretion of IL-13 by VK2 cells (Figure 4), which was also affected by curcumin; and thus, under NF- $\kappa B$-mediated regulation (Figure 5). There were no significant effects of lactobacilli on VK2 cell secretion of IL-6 (Figure 4).

\section{Discussion}

Vaginal epithelial cells have the capacity to respond to an encounter with $C$. albicans by production of proinflammatory cytokines that can recruit host defenses to the infected tissue [9]. The influx of inflammatory cells

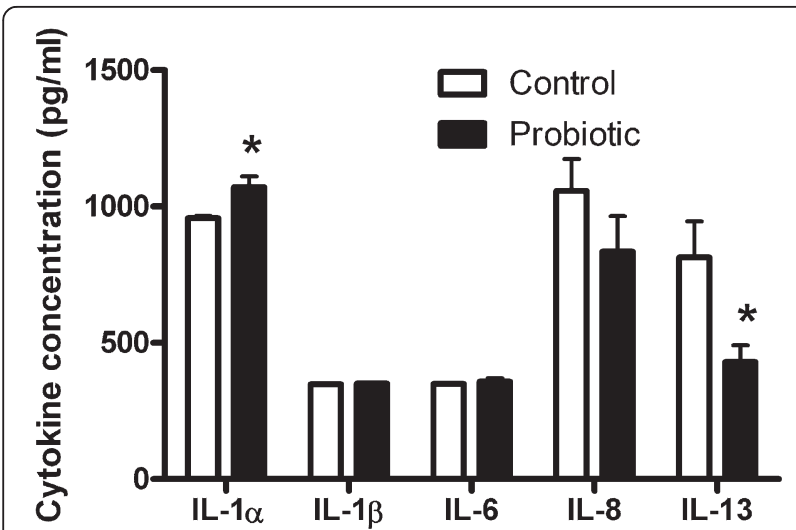

Figure 4 Probiotic effects on VK2 cells secretion of cytokines.

The mean \pm standard error concentrations of cytokines secreted into the basolateral medium by VK2 cells incubated with 17 $\beta$-estradiol, infected with $C$. albicans (open bars) and by VK2 cells incubated with $17 \beta$-estradiol, infected with $C$. albicans after treatment with probiotic lactobacilli (solid bars) are compared. *The probiotictreated group is significantly different from the control group by the paired $t$-test, $P<0.05$

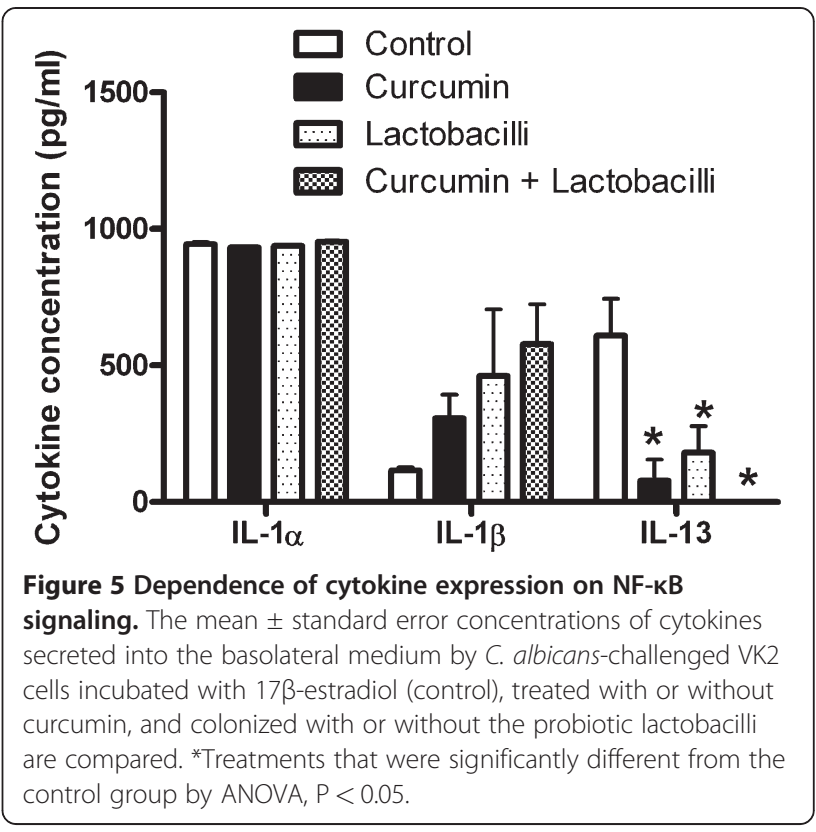

results in local tissue damage that contributes to the morbidity of vaginal yeast infections. A review of clinical trials with lactobacilli to treat VVC currently reveals a lack of efficacy in curing C. albicans infections [16]. Wira, et al. [10], suggest that specific strains, like $L$. rhamnosus GR-1 and L. reuteri RC-14, may show some promise for treatment, but larger clinical studies are needed to know for sure.

Even if they do not cure VVC, the probiotic lactobacilli, L. rhamnosus GR-1 and $L$. reuteri $\mathrm{RC}-14$, reduce the symptoms of vaginal yeast infections in conjunction with fluconazole treatment [17]. This suggests that there could be a host response effect by these strains beyond their role in colonization resistance. The present study was conducted to determine if there is a mechanism by which pro-inflammatory VK2 cell responses to C. albicans are affected by these Lactobacillus spp. strains. Since estrogen plays a critical role in the pathogenesis of VVC, the role of estrogen in the VK2 cell response to $C$. albicans was also evaluated.

Vaginal epithelial cells may detect C. albicans surface molecules with Toll-like receptors TLR2 and TLR4 [8], and possibly TLR6 $[9,18]$, which signal through the NF$\kappa B$ signal transduction pathway to initiate transcription of mRNA for pro-inflammatory cytokines. In the present study, probiotic bacteria suppressed expression of genes associated with the NF- $\mathrm{KB}$ signal transduction pathway and expression of TNFa and IL-8 mRNA in C. albicansinfected VK2 cells. Expression of TLR2 and TLR6 were induced in VK2 cells by contact with $C$. albicans, which has also been observed in normal human gingival epithelial cells infected with Candida famata [19]. These receptors appear to be important for epithelial cell 
recognition of $C$. albicans. $17 \beta$-estradiol decreased TLR2 and TLR6 expression by VK2 cells, suggesting that the hormone might leave cells less able to respond to the presence of $C$. albicans through production of immune recruitment cytokines. The presence of the probiotic lactobacilli also decreased TLR2 and TLR6 mRNA.

Since Toll-like receptors activate proinflammatory cytokine production via the NF- $\mathrm{BB}$ signal transduction pathway $[8,9]$, it seemed pertinent to observe how expression of genes involved in this pathway and the cytokines they induce were affected by C. albicans, estrogen, and the probiotic lactobacilli. The increased VK2 cell expression of NF- $\mathrm{kB}$-associated genes and cytokines ELK1, IкK $\beta$, IL-6, and TNF $\alpha$ by $C$. albicans challenge is consistent with induction of the TLR2/6-mediated transduction of signals through the NF- $\mathrm{kB}$ pathway to produce inflammatory signals, e.g., IL6 and TNF $\alpha$.

Vaginal epithelial cells appear to have the capacity to produce a number of different cytokines that can recruit innate and adaptive immune responses. For example, antigens from $C$. albicans induce vaginal epithelial cell line A431 production of inflammatory cytokines: IL-1 $\alpha$, IL-1 $\beta$, IL-6, IL-8, IL-10, GM-CSF, IFN $\gamma$, and TNF $\alpha$ [12]. In our present study, the VK2 (E6/E7) cell line produced measurable amounts of IL- $1 \alpha$, IL-1 $\beta$, IL-6, IL- 8 , and TNF $\alpha$, but not IFN $\gamma$ and IL-10 when challenged with $C$. albicans. IL-13 was also detected by immunoassay. Therefore, this cell line is capable of producing cytokines that can recruit innate immunity but not IFN $\gamma$ and IL10, which are mostly produced by lymphocytes. Experiments conducted with the same VK2 cell line and Lactobacillus spp. strains as the present study reported stimulation of IL- $1 \alpha$ expression by $C$. albicans challenge, but not after subsequent challenge with the lactobacilli [20]. The latter study reported an increase in IL-8 expression by VK2 cells when the lactobacilli were present, which is what our present study shows in the absence of $17 \beta$-estradiol. VK2 cells responded differently to $17 \beta$ estradiol when $C$. albicans was not present, as they had increased expression of IL-1 $\beta$ and reduced expression of IL-8, suggesting a complicated regulatory process during the simultaneous influence of $C$. albicans and estrogen. Experimental examples show the complexity of C. albicans surface molecules and estrogen effects on cytokine production. It is known that bacterial surface molecules induce IL-1 $\beta$, IL-6, and IL- 8 in vaginal secretions [21]. C. albicans surface molecules induce Il-8 and TNF $\alpha$ mRNA by vaginal epithelial cells, which store translated cytokine proteins for secretion in a temporally dissociated manner [8]. This may explain why our experiments did not show increased amounts of IL- $1 \beta$ and IL- 8 in the supernatants from VK2 cells with mRNA induction. Estrogen differentially regulates expression of 3000 genes in the vaginal epithelium, including the repression of IL-8 [22]. In polarized uterine epithelial cells, estradiol represses poly (I:C)-induced expression of $\mathrm{IL}-8$ and reverses IL-1 $\beta$ induction of TNF $\alpha$ and IL- 8 expression [23]. Similar experiments have not been described for vaginal epithelial cells until the present study.

The probiotic lactobacilli suppressed expression of NF- $\kappa B$ pathway-associated genes I $\kappa \alpha \alpha$, and ELK1, which were induced by $C$. albicans infection of the VK2 cells. They also inhibited the additive effect of $17 \beta$-estradiol on C. albicans-induced TNF $\alpha$. These results support the role of $C$. albicans acting through Toll-like receptors and the NF- $\mathrm{B}$ signal transduction pathway in VK2 cells to activate expression of inflammatory cytokines, which is suppressed by the presence of probiotic lactobacilli. Although the probiotic lactobacilli appear to suppress proinflammatory responses, their presence is associated with increased VK2 cell expression of IL- $1 \alpha$ and IL- $1 \beta$, which can recruit cellular mediators of immunity. The pro-inflammatory cytokines IL- $1 \alpha$ and IL-1 $\beta$ were expressed in greater amounts as a result of the probiotic bacteria and their expression was not abrogated by the NF- $\mathrm{kB}$ pathway inhibitor, curcumin. An alternative signal transduction response pathway to NF- $\mathrm{B}$, such as the MAPK pathway via the AP-1 transcription factor, could elicit an immunological cell recruitment response to $C$. albicans. It has been shown that IL-1 $\beta$ is involved in the stimulation of $\beta$-defensin expression by esophageal epithelial cells in Candida esophagitis via both the NF- $\kappa \mathrm{B}$ and MAPK/AP-1 signal transduction pathways [24]. The conclusion based on these results is that probiotic lactobacilli suppress the TLR2/6-initiated NF$\mathrm{\kappa B}$-mediated induction of some pro-inflammatory cytokines, while stimulating another signal transduction pathway that induces IL- $1 \alpha$ and IL- $1 \beta$ expression. The importance of IL-1 $\beta$ in stimulating an anti-Candida spp. response is exemplified by the apparent implementation of multiple signal transduction pathways for induction of its expression.

\section{Conclusions}

The L. rhamnosus GR-1 and L. reuteri $\mathrm{RC}-14$ strains are used in commercial probiotic products for maintenance of vaginal health. The present study agrees with other studies, including in vivo studies [1], that they inhibit infectivity of $C$. albicans, the major cause of vulvovaginal candidiasis. The results of this present study show that L. rhamnosus GR-1 and $L$. reuteri $\mathrm{RC}-14$ may directly influence the way vaginal epithelial cells respond to $C$. albicans infections and how host defenses are recruited to the vaginal mucosa. Perhaps, the major influence on the vaginal epithelial cells from the lactobacilli is to direct the recruitment of a better host response to the site of C. albicans infection, one that limits damage from excessive inflammation but not the cell-mediated immune 
response. This study shows that the effects of the probiotic lactobacilli may be helpful, in that inflammation may be reduced, but not at the expense of immune effector cell recruitment via IL-1 production.

\section{Abbreviations \\ CFU: Colony-forming units; GTS: Genital tract secretions; K-SFM: Keratinocyte- serum free medium; mRNA: Messenger ribonucleic acid; MRS: deMann Rogosa Sharpe medium; PBS: Phosphate-buffered saline; qRT- PCR: Quantitative real-time polymerase chain reaction; TEER: Transepithelial electrical resistance; WC: Vulvovaginal candidiasis.}

\section{Competing interests}

The authors declare that they have no competing interests.

\section{Acknowledgements}

This work was supported by funds from the Food and Drug Administration of the Public Health Service. The authors thank Dr. Mark Hart and Dr. Marli Azevedo for critical review of the manuscript. The opinions expressed in this manuscript are the authors' and do not necessarily reflect the position of the Food and Drug Administration.

\section{Authors' contributions}

RDW conceived of and designed the experiments, conducted the statistical analyses, conducted the flow cytometry and cytokine immunoassays, and wrote the manuscript. SJJ conducted the quantitative real-time PCR analyses and cell culture procedures. All authors read and approved the final manuscript.

Received: 21 February 2012 Accepted: 20 June 2012

Published: 20 June 2012

\section{References}

1. Falagas ME, Betsi Gl, Athanasiou S: Probiotics for prevention of recurrent vulvovaginal candidiasis: a review. J Antimicrob Chemother 2006, 58:266272

2. Sobel JD: Vulvovaginal candidosis. Lancet 2007, 369:1961-1971.

3. Reid G, Bruce AW: Urogenital infections in women: can probiotics help? Postgrad Med J 2003, 79:428-432.

4. Barousse MM, Espinoza T, Dunlap K, Fidel PL Jr: Vaginal epithelial cell antiCandida albicans activity is associated with protection against symptomatic vaginal candidiasis. Infect Immun 2005, 73:7765-7767.

5. Fidel PE Jr: History and update on host defense against vaginal candidiasis. Am J Reproduct Immunol 2007, 57:2-12.

6. Cremel M, Berlier W, Hamzeh $\mathrm{H}$, Cognasse $\mathrm{F}$, Lawrence $\mathrm{P}$, Genin $\mathrm{C}$, Bernengo J-C, Lambert C, Dieu-Nosjean M-C, Delézay O: Characterization of CCL20 secretion by human epithelial vaginal cells: involvement in Langerhans cell precursor attraction. J Leukoc Biol 2005, 78:158-166.

7. Peterson ML, Ault K, Kremer MJ, Klingelhutz AJ, Davis CC, Squier CA, Schlievert PM: The innate immune system is activated by stimulation of vaginal epithelial cells with Sataphylococcus aureus and toxic shock syndrome toxin 1. Infect Immun 2005, 73:2164-2174

8. Pivarcsi A, Nagy I, Koreck A, Kis K, Kenderessy-Szabo A, Szell M, Dobozy A, Kemeny $L$ : Microbial compounds induce the expression of proinflammatory cytokines, chemokines and human $\beta$-defensin- 2 in vaginal epithelial cells. Microbes Infect 2005, 7:1117-1127.

9. McGowin CL, Ma L, Martin DH, Pyles RB: Mycoplasma genitalium-encoded MG309 activates NF-KB via toll-like receptors 2 and 6 to elicit proinflammatory cytokine secretion from human genital epithelial cells. Infect Immun 2009, 77:1175-1181.

10. Wira CR, Fahey JV, Ghosh M, Patel MV, Hickey DK, Ochiel DO: Sex hormone regulation of innate immunity in the female reproductive tract: the role of epithelial cells in balancing reproductive potential with protection against sexually transmitted pathogens. Am J Reprod Immunol 2010, 63:544-565

11. Fichrova RN, Rheinwald JG, Anderson DJ: Generation of papillomavirusimmortalized cell lines from normal human ectocervical, endocervical and vaginal epithelium that maintain expression of tissue-specific differentiation proteins. Biol Reproduct 1997, 57:847-855.
12. Schaller M, Zakikhany K, Naglik JR, Weindl G, Hube B: Models of oral and vaginal candidiasis based on in vitro reconstituted human epithelia. Nat Protocol 2006, 6:2767-2773.

13. Kinsman OS, Collard AE: Hormonal factors in vaginal candidiasis in rats. Infect Immun 1986, 53:498-504.

14. Geshnizgani AM, Onderedonk AB: Defined medium simulation genital tract secretions for growth of vaginal microflora. J Clin Microbiol 1992, 30:1323-1326.

15. Motulsky H: Choosing an appropriate sample size, Intuitive Biostatistics. New York: Oxford University Press; 1995:195-204.

16. Abad CL, Safdar N: The role of Lactobacillus probiotics in the treatment or prevention of urogenital infections - a systematic review. J Chemother 2009, 21:243-252.

17. Martinez RCR, Franceschini SA, Patta MC, Quintana SM, Candido RC, Ferreira JC, De Martinis ECP, Reid G: Improved treatment of vulvovaginal candidiasis with fluconazole plus probiotic Lactobacillus rhamnosus GR-1 and Lactobacillus reuteri RC-14. Lett Appl Microbiol 2009, 48:269-274.

18. Netea MG, van de Veerdonk F, Verschueren I, van der Meer JWM, Kullberg BJ: Role of TLR1 and TLR6 in the host defense against disseminated candidiasis. FEMS Immunol Med Microbiol 2008, 52:118-123.

19. Bahri R, Saidane-Mosbahi D, Rouabhia M: Candida famata modulates tolllike receptor, $\beta$-defensin, and proinflammatory cytokine expression by normal human epithelial cells. J Cell Physiol 2009, 222:209-218.

20. Martinez RCR, Seney SL, Summers KL, Nomizo A, De Martinis ECP, Reid G Effect of Lactobacillus rhamnosus GR-1 and Lactobacillus reuteri RC-14 on the ability of Candida albicans to infect cells and induce inflammation. Microbiol Immunol 2009, 53:487-495.

21. Basso B, Giménez F, López C: IL-16, IL-6 and IL-8 levels in gyneco-obstetric infections. Infect Dis Obstet Gynecol 2005, 13:207-211.

22. Coutreau MM, Chennathukuzhi VM, Harris HA, Han L, Dorner AJ, Apseloff G, Varadarajan U, Hatstat E, Zakaria M, Strahs AL, Crabtree JS, Winneker RC, Jelinsky SA: A study of $17 \beta$-estradiol-regulated genes in the vagina of postmenopausal women with vaginal atrophy. Maturitas 2007, 58:366376

23. Fahey JV, Wright JA, Shen L, Smith JM, Ghosh M, Rossoll RM, Wira CR: Estradiol selectively regulates innate immune function by polarized human uterine epithelial cells in culture. Mucosal Immunol 2008, 1:317325

24. Pahl R, Brunke G, Steubesand N, Schubert S, Böttner M, Wedel T, Jürgensen C, Hampe J, Schäfer H, Zeissig S, Schreiber S, Rosenstiel P, Reiss K, Arlt A: IL$1 \beta$ and ADAM17 are central regulators of $\beta$-defensin expression in Candida esophagitis. Am J Physiol 2011, 300:G547-G553.

doi:10.1186/1423-0127-19-58

Cite this article as: Wagner and Johnson: Probiotic lactobacillus and estrogen effects on vaginal epithelial gene expression responses to Candida albicans. Journal of Biomedical Science 2012 19:58.

\section{Submit your next manuscript to BioMed Central and take full advantage of:}

- Convenient online submission

- Thorough peer review

- No space constraints or color figure charges

- Immediate publication on acceptance

- Inclusion in PubMed, CAS, Scopus and Google Scholar

- Research which is freely available for redistribution 